\title{
Behavioural effects of a health-related cycling campaign in Denmark: Evidence from the national travel survey and an online survey accompanying the campaign
}

\author{
Nielsen, Thomas Alexander; Haustein, Sonja
}

Published in:

Journal of Transport \& Health

Link to article, DOI:

10.1016/j.jth.2018.12.003

Publication date:

2019

Document Version

Peer reviewed version

Link back to DTU Orbit

Citation $(A P A)$ :

Nielsen, T. A., \& Haustein, S. (2019). Behavioural effects of a health-related cycling campaign in Denmark:

Evidence from the national travel survey and an online survey accompanying the campaign. Journal of Transport \& Health, 12, 152-163. https://doi.org/10.1016/j.jth.2018.12.003

\section{General rights}

Copyright and moral rights for the publications made accessible in the public portal are retained by the authors and/or other copyright owners and it is a condition of accessing publications that users recognise and abide by the legal requirements associated with these rights.

- Users may download and print one copy of any publication from the public portal for the purpose of private study or research.

- You may not further distribute the material or use it for any profit-making activity or commercial gain

- You may freely distribute the URL identifying the publication in the public portal 
Thomas Alexander Sick Nielsen

3 Sonja Haustein, DTU Management Engineering

4

5 Behavioural effects of a health-related cycling campaign in Denmark: evidence from the national travel survey and an online survey accompanying the campaign

\section{Abstract}

Introduction

With the overall aim to improve people's health through increased physical activity, an extensive cycling campaign was conducted in Denmark from 2015-2017. The campaign included local activities concentrated in four partner municipalities across the country and national campaign activities. After one year, the “cycling coach”, a customised smart phone application to support cyclists in goal setting and goal achievement, was launched and promoted. This paper describes the campaign, how it was evaluated, and which behavioural effects it generated.

\section{Methods}

17 We measured the behavioural effect of the campaign based on two data sets: the Danish National

18 Travel survey and a survey that was conducted as part of the project evaluation and monitored the cycling frequency before, during and after the campaign. Regression analyses modelling the likelihood of cycling based on travel survey data (logistic regression) and cycling frequency

21 based on the project survey (linear regression) were conducted. In the analyses, the accumulated

22 campaign activities in the respondents' municipality at time of measurement was included as the

23 independent variable while controlling for socio-demographic, spatial and time-related factors.

\section{Results}

25 Both regression analyses showed a significant effect of the campaign intensity on cycling. We 26 assessed that at least 21 million cycling trips were conducted because of campaign activities. 
27 Conclusions

28 Based on the project experience, we discuss ways to improve future cycling campaigns and their 29 evaluation, for example by allocating sufficient resources for establishing a strong partnership 30 among cross-sectional partners and for a more detailed documentation of campaign activities.

31 Keywords: Bicycling, intervention, behavior change, campaign, effect assessment 


\section{Introduction}

Although Denmark shows high levels of cycling compared to most other European countries (Haustein \& Nielsen, 2016), problems from individualised motorized transport persist and cause serious environmental and health-related problems. Especially cities suffer from air and noise pollution and urgently require actions that make urban life more healthy and liveable. An increased share of cycling is regarded as part of the solution to the social, economic and environmental problems that many cities face and local cycling policies play an important role in achieving this increase (Lanzendorf \& Busch-Geertsema, 2014; Pucher, Dill et al., 2010). the reduction of air and noise pollution (e.g., de Nazelle et al., 2011; Rabl \& de Nazelle, 2012). According to an assessment based on commuting data from Stockholm county, a shift from the car to the bicycle for commuting, of all people living in a 30 minute cycling distance from work, would result in more than 449 years of life saved annually for that area based on reduced vehicle emission and related exposure (Johansson et al., 2017). Additionally, increased numbers of cyclists reduce the risk of collisions with motorists, as the visibility of cyclists improves (e.g., Jacobsen, 2003; Pucher, Buehler et al., 2010).

A shift from passive to active transport modes like cycling has also been shown to result in individual health benefits through increased physical activity that clearly outweigh potential risk from traffic accident involvement and inhaled air pollution (e.g., Deenihan \& Caulfield, 2014; de Hartog et al., 2010; Mueller et al., 2015; Pucher, Buehler et al., 2010; Rabl \& de Nazelle, 2012). More specifically, research identified negative relations between active travel and cardiovascular risk (e.g., Laverty et al., 2013; Millett et al. 2013) and diabetes and obesity (e.g., Pucher, Buehler et al, 2010).

To increase cycling levels, various intervention studies have been carried out and assessed in terms of achieving modal shifts and related health effects. Reviews on the achievable effects by intervention studies show mixed results. A review study that assessed the effectiveness of different behavioural change techniques to promote walking and cycling found that the inclusion of self-monitoring and intention-formation techniques is most promising (Bird et al., 2013). This is also in line with recommendations derived from behaviour theory, which moreover stresses the need to support people differently, depending on their current stage of 
62 behaviour change (e.g., Bamberg et al., 2011; Gatersleben \& Appleton, 2007): People who have 63 no intention to start or increase cycling first need to be informed about the potential benefits of 64 cycling (and/or the negative effects of not cycling), while people who have already formed this 65 intention rather need assistance in formulating specific personal goals and information on how to 66 achieve these goals. Finally, people who have already started to increase cycling need feedback 67 and social support to maintain the new behaviour and transfer it into a new habit.

When differentiating between interventions that either promote cycling specifically or a change of travel behaviour more generally, clearer evidence was found for cycling specific interventions (Yang et al., 2010). For interventions applied at population level, net increases of up to 3.4 percentage points could be identified (Yang et al., 2010). Addressing larger populations

72 (e.g., whole cities) instead of individuals or groups is also supported by a review with special 73 focus on how to increase commuter cycling: even when population-wide interventions have only 74 small effects, the overall effect is larger as they reach out to more people (Stewart et al., 2015). 75 Pucher, Dill et al. (2010) stresses the need of comprehensive efforts and integrated packages of interventions instead of individual, uncoordinated interventions. As other review studies, they also point to methodological deficits of many existing intervention studies (Arnott et al., 2014;

78 Bird et al., 2013; Pucher, Dill et al., 2010; Scheepers et al., 2014; Yang et al., 2010), where robust evidence for the success of cycling campaigns is still missing (Stewart et al., 2015).

On this background, the aim of this study was to evaluate the behavioural effects from a population-wide cycling campaign in Denmark that was inspired by theory and evidence on which measures appear most promising in achieving a modal shift to cycling.

The following section describes the cycling campaign in more detail. Section 3 presents the database of the effect assessment as well as the applied method of data analysis. Section 4 provides descriptive results on cycling in Denmark before, during, and after the campaign.

86 Subsequently, the results of the effect analyses are shown. Section 5 discusses results and

87 limitations and draws conclusions on how to improve future campaigns and their evaluation 88 based on the experience from the project process and results. 
The cycling campaign this paper focusses on was conducted in four partner municipalities in Denmark: Frederiksberg, Aarhus, Odense, and Middelfart. The cities vary considerably in size and cycling levels and are located in different regions of Denmark, as shown in Table 1.

Table 1: Description of partner municipalities

\begin{tabular}{lclll}
\hline $\begin{array}{l}\text { Partner } \\
\text { municipality }\end{array}$ & Inhabitants & Region & $\begin{array}{l}\text { Residents modal split, } \\
\text { cycling, walking, public, } \\
\text { car }\end{array}$ & $\begin{array}{l}\text { Average trip } \\
\text { length }\end{array}$ \\
\hline Frederiksberg & 104.410 & Zealand & $32 \%, 28 \%, 14 \%, 25 \%$ & $10 \mathrm{~km}$ \\
Aarhus & 340.421 & East of Jutland & $21 \%, 23 \%, 8 \%, 48 \%$ & $13 \mathrm{~km}$ \\
Odense & 202.348 & Southern Denmark & $24 \%, 19 \%, 4 \%, 51 \%$ & $12 \mathrm{~km}$ \\
Middelfart & 38.210 & Funen & $10 \%, 13 \%, 3 \%, 70 \%$ & $20 \mathrm{~km}$ \\
\hline
\end{tabular}

95

The overall goal of the campaign project was to increase cycling in Denmark by one percentage point, which equals circa 50 million additional cycling trips per year. In particular, this was expected to be achieved through a shift from the car to the bike for short trips (up to 5 $\mathrm{km})$. The increased level of long-term physical activity was expected to contribute to the prevention of non-communicable, lifestyle related diseases and medical conditions including diabetes, coronary heart diseases, and four types of cancer. Accordingly, the partnership behind the project included the Danish Cancer Society (project owner), the Danish Diabetes Association, and the Danish Heart Foundation. The other partners were two transport organisations (DSB, Movia), the Danish Cyclist Federation, and the above-mentioned partner municipalities.

The campaign activities included different elements: national media activities (e.g., press releases, national campaign promotions, flyers distributed to households), social-media campaigns on Instagram and Facebook (e.g., campaign sites, quests, photo contests), and local events such as cycling services, lotteries, and the distribution of small incentives (e.g., bicycle bells, oil, coffee cups) along with project flyers and personal information. Figure 1 provides some examples of campaign material. The main argument used to motivate people to cycle was the positive (physical and mental) health effects of cycling. The project's communication guideline included - among other aspects - that all communication should be positive, supportive, motivating, concrete, personal, and evidence-based. 
The events and media campaigns were also used to promote one central element of the campaign - the "cycling coach” (launched in April 2016, see Figure 1). The cycling coach is a smartphone app, developed as part of the project, to motivate people to cycle (more). The app asked users to set a specific goal for the number of days per week that they would like to cycle. In addition, app users were requested to provide their present cycling frequency and their motivation to increase cycling. This information was used to profile users and defined the personalised content of the 'coaching' that each user received. Each user could monitor his/her personal cycling goal with the app. Goal fulfilment was 'celebrated’ by the app, including an opportunity to post successes on social media (Facebook and Instagram).

The cycling coach automatically registered cycling trips based on GPS and accelerometer data, which was used as a basis for feedback on personal goal achievement. Depending on the level of goal achievement, personalised messages were sent to the users to increase their motivation and eventually adjust their personal goal.

The different elements of the campaign were created to support people at different stages in the process of behaviour change (e.g., Bamberg et al., 2011, Bamberg, 2013; Gatersleben \& Appleton, 2007) and provided through various channels. More general information about cycling and health were provided via different media channels and at doctors and health centres aiming for awareness raising among people who had not formed an intention to increase cycling yet. For people who already had an intention to increase cycling, the cycling app should help to set a realistic goal, while the app supported goal achievement by feedback, self-monitoring and social support.

Being a national campaign that specifically focused on increasing cycling and that used awareness raising, feedback, self-monitoring and goal-setting techniques as techniques of behaviour change, the campaign was built upon assumptions derived from behaviour theory (Bamberg et al., 2011) and evidence from evaluation studies (e.g., Bird et al., 2013; Yang et al., 2010) on what is most useful in increasing cycling. Still, each campaign partner was free to add elements according to own possibilities and interests as long as they fitted within the overall strategy and communication guidelines. Frederiksberg municipality, for example, used the info screens in local health centers for promotion of the app. In Odense, campaign material was sent to all households. 
146 (year and month), which material they distributed, and how many people they approximately

147 reached.

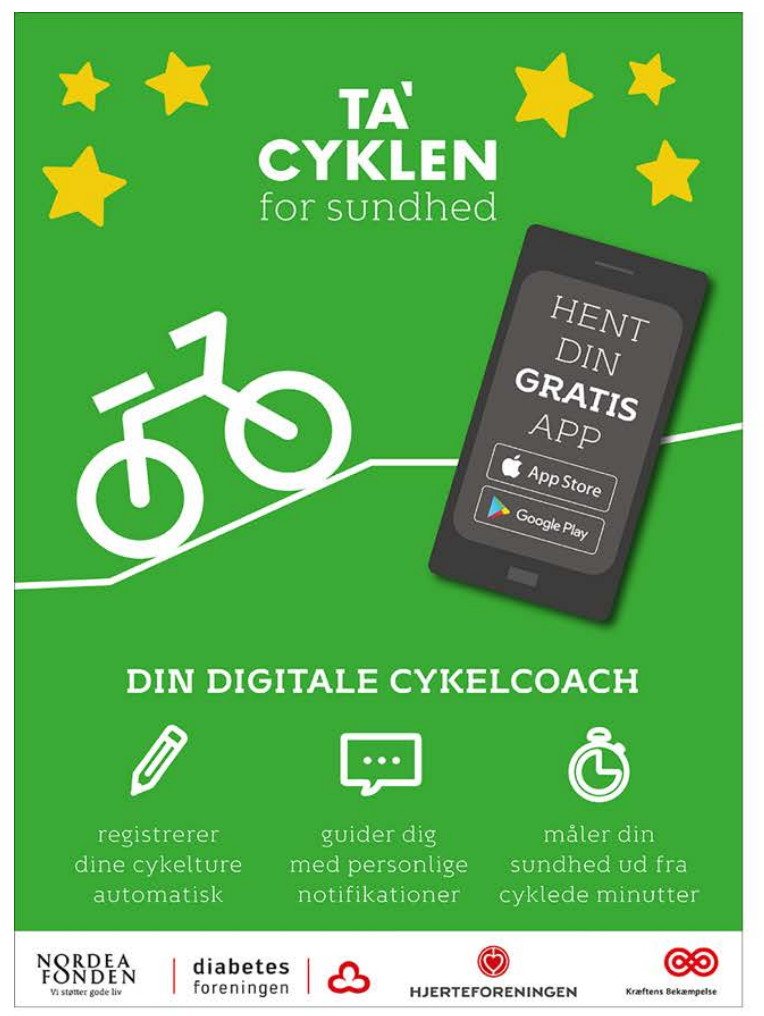

a) Advertisement for the app as poster at local doctors and health-centres

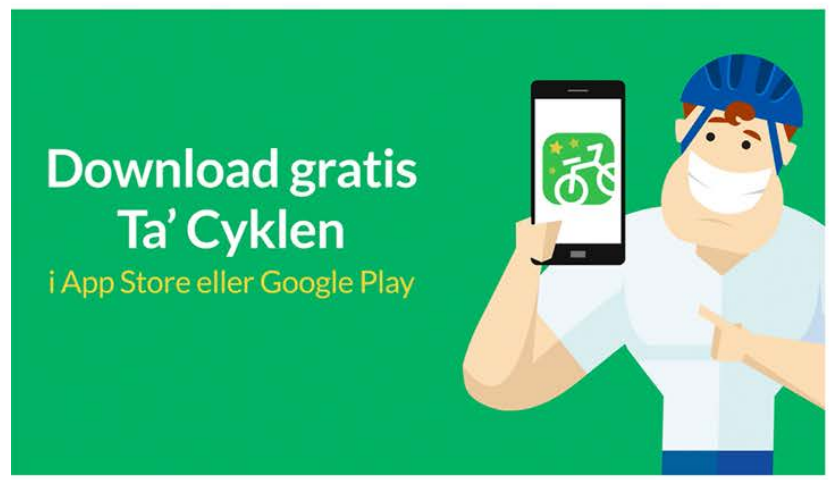

c) Advertisement for the "cycling coach" used in social media

\section{Figure 1: Examples of material used in the campaign.}

\section{Material and methods}

\subsection{Survey data}

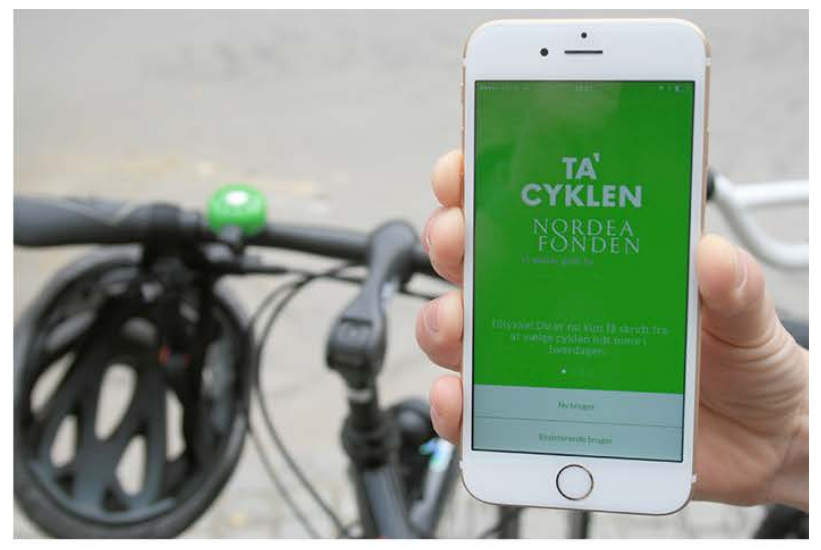

b) The "cycling coach" on a smart phone

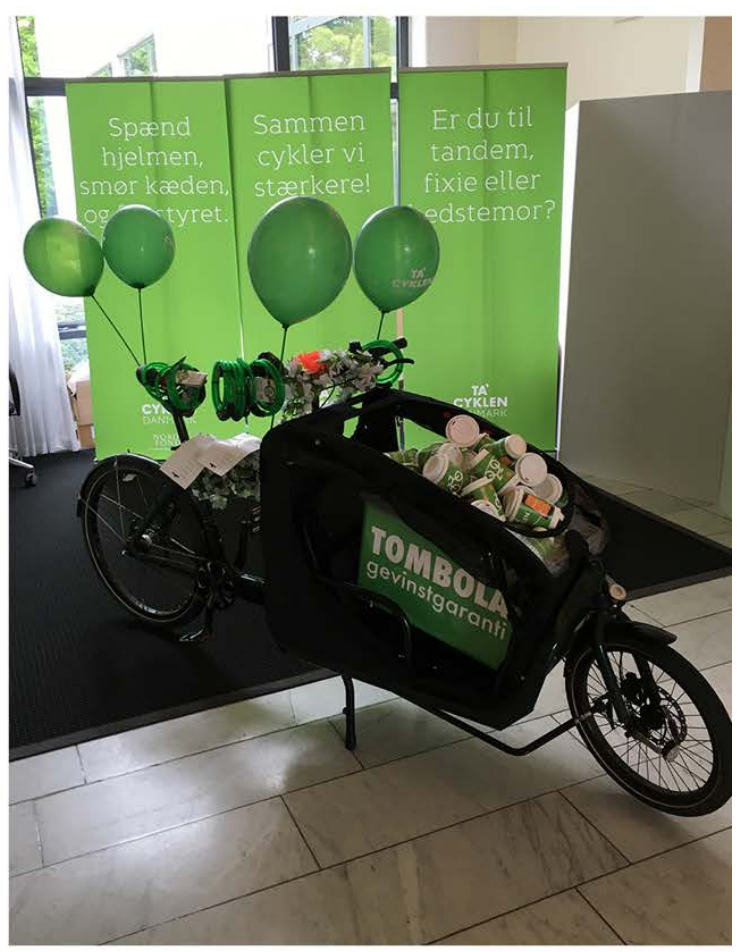

d) Photo from a local event (before opening) 
The effect assessment is based on two different independent data sources: the National Travel Survey of Denmark (Transportvaneundersøgelsen, TU, see Christiansen \& Skougaard, 2015) and a representative survey that monitored the awareness of the campaign and its single elements, cycling levels, and factors that may affect cycling before, during, and after the campaign (Kendsskabundersøgelse, KU).

TU contains a one-day travel diary of Danish residents aged 10-84 years. Besides details on travel activities the day before, the survey asks about a variety of background variables (e.g., gender, age, place of residence, income, education, car and bike ownership). TU is based on a combination of web and telephone interviews. Each respondent receives an introductory letter, including a personal link to the web survey. Respondents who do not complete the web interview within two days are selected for telephone interviews. The survey's response rate is on average 58\%, data is collected continuously (Christiansen \& Skougaard, 2015).

For this study, we used a TU data set covering the period from July 2010 to August 2017 including 280,000 trips by survey-respondents (age 10-85) with all modes of transportation, so that we could analyse the impact of the campaign on the use of a bicycle on a trip, based on the place of residence and the campaign intensity in the place of residence.

KU was conducted as an online survey with six waves of data collection from February 2015 to June 2017. Data were collected based on an online panel of the market research institute EPINION. The panel ("Danmarkspanelet”) consists of approx. 240,000 members covering all regions of Denmark. The first survey was completed before the first campaign activities began (baseline measurement), the last one was conducted circa one month after the last activity. In each wave, a national representative sample of about 1000 participants was included and an additional data collection among residents in each partner municipality of about 200 per municipality. The complete KU dataset comprises 11.798 participants.

The questionnaire covered the following topics: awareness of the campaign and its elements (e.g., the cycling coach app); cycling and driving frequency, considerations about changing cycling and driving habits, attitudes and norms related to cycling and driving, sociodemographic factors. The cycling frequency was included as a question on the number of cycling days per week or month. Questioning the occurrence of cycling days was based on the experience from previous questionnaires (Olafsson et al., 2016) and provided an approach to 
cover cycling frequency without the ambiguity associated with asking respondents to account for their trips. The question was implemented as an ordinal scale with categories: 'never', 'no cycling in the past month', '1-2 days in the last month', '2-3 days in the last month', '1-2 days in the last week', '3-4 days in the last week', '5-6 days in the last week', and 'every day'. The scale was adapted to increase sensitivity towards changes in low-frequency cycling as this was thought to be a likely outcome of the campaign.

\subsection{Measurement of campaign intensity}

To measure and quantify the development and impact of the campaign, a campaign log was developed. Originally, campaign partners were asked to register all campaign activities in terms of date, municipality, duration, activity, resources employed, target group, number of sites involved, as well as number of handouts and/or attendance in the campaign log. However, it was not possible to collect this information in a comparable format on all occasions. Instead, we operationalised the campaign intensity for each partner municipality as the number of sites with activities per month. This operationalisation has the advantage of allowing for a scale measure of the increase in campaign intensity over time and it provides large differences in the volume of campaign activities between the participating municipalities.

The ideal campaign intensity measure could have involved a more direct measure of contacts or exposure, or measures of resource spending. This was not possible due to the open nature of the campaign and its development, which also included use of unpaid volunteers. However, with the operationalised measure we do achieve a substantial improvement compared with simpler binary representations of campaign participation, which would otherwise have been the alternative. We also achieve a measure, which is independent from the behaviour data that is used to measure the campaign effect.

Local campaign activities were launched with events in local supermarkets of the same food store chain in all partner municipalities by March 2015, later events targeted cycling to public transport hubs (September 2015). In 2016, the local campaign activities diversified and intensified, based on local cycling teams, events and communication channels. Activities included distribution of campaign material to all households (Odense, April 2016), bicycle repair/assistance to promote the coach and the campaign message (Aarhus, April 2016), digitalbanners on urban arterials (Aarhus, October 2016). To a lesser degree, the locations for 
212 campaign activities also spread to municipalities beyond the four original partner municipalities.

213 The highest campaign intensity was in April and October 2016 - the beginning and end of the

214 cycling season. Parallel to this, a number of national activities were carried out based on

215 nationwide media or the networks of the partner organisations. These activities cannot be

216 compared to local activities. They included the launch of the cycling coach on Facebook

217 supported by the web-channels of the partner organisations, a national press release, distribution

218 of campaign material by volunteers to bike-shops and health-centres, as well as infographics and

219 animations in public transport media in the Capital region. These activities have been summed

220 up as a variety of events / activities at different times, but with no specific geography. Figure 2

221 shows the cumulated national and local campaign activities during the project period. The local

222 campaign activities are shown separately for each municipality with local events or activities.

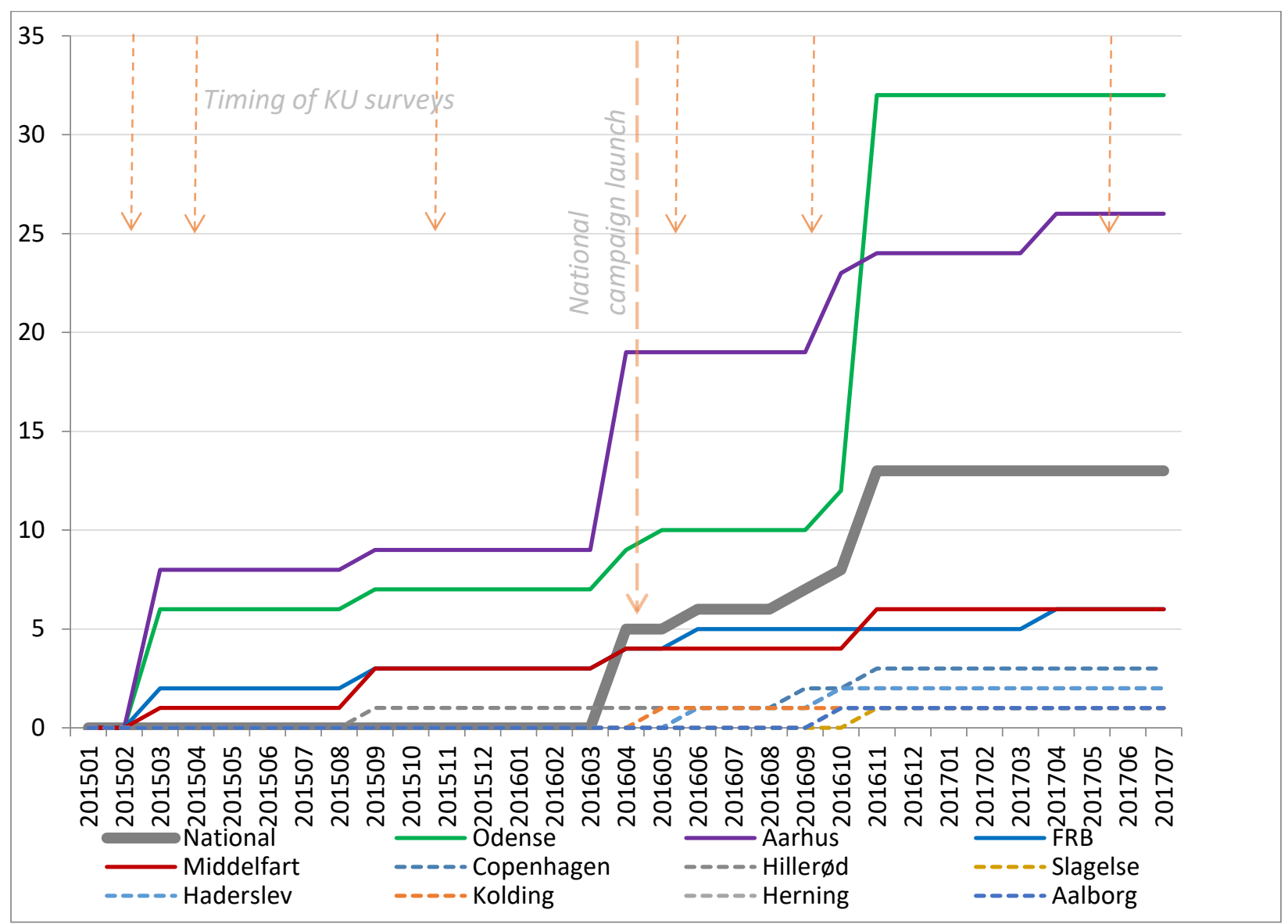

Figure 2: Cumulated national and local campaign activities during the project period.

225 Notes: Timing of KU-survey waves and the beginning of the national part of the campaign is

226 indicated with arrows. Local campaign activities are summarized from the number of locations 
227 with activities in each municipality. The continuous lines relate to partner municipalities, the

228 interrupted lines to non-partner municipalities with local campaign activities.

\section{$229 \quad 3.3 \quad$ Analysis of behavioural effects}

Behavioural effects were estimated based on regression analyses. We used two

231 independent datasets to estimate the effects - TU data and KU data (see Section 2.1). We

232 expected that the real effect lies within the range of both estimations and that similar values

233 based on both datasets would indicate high reliability of the results.

The regression analysis based on TU data was a logistic regression using the information whether a trip was a cycling trip or not as dependent variable. In the regression analysis based on

$236 \mathrm{KU}$ data, the number of cycling days per month for each survey participant was the dependent

237 variable. In both analyses, the campaign effect was estimated based on the cumulated local

238 campaign activity, which varied between 6 and 32 among partner municipalities, and between 0

239 and 3 for non-partner municipalities. We also used the same (when available) or similar (when

240 not available) control variables in both regression analysis.

241 Based on the estimated campaign effects from the regression analyses, we estimated how many

242 additional cycling trips were conducted because of the campaign. Based on information from TU

243 data on average number of cycling trips per day and cycling trip length within the partner

244 municipalities, these numbers were transferred to cycling trips and kilometres per persons per

245 month. Descriptive statistics presenting the TU and KU datasets are included in Table 2 and

246 Table 3.

247 Table 2: Descriptive statistics for the TU dataset.

\begin{tabular}{lll}
\hline Variable: & Distribution or mean and SD values: \\
\hline Survey year & $2010: 14 \%$ & $2014: 11 \%$ \\
& $2011: 22 \%$ & $2015: 10 \%$ \\
& $2012: 12 \%$ & $2016: 11 \%$ \\
& $2013: 10 \%$ & $2017: 8 \%$ \\
\hline Survey month & Jan: $7 \%$ & Jul: $9 \%$ \\
& Feb: $7 \%$ & Aug: $9 \%$ \\
& Mar: $8 \%$ & Sep: $9 \%$ \\
& Apr: $8 \%$ & Oct: $9 \%$ \\
& May: $8 \%$ & Nov: $9 \%$ \\
& Jun: $8 \%$ & Dec: $8 \%$ \\
\hline Daytype & Weekdays: $57 \%$ & Saturday: $13 \%$ \\
& Friday: $15 \%$ & Sunday: $11 \%$ \\
& Weekday in holiday: $2 \%$ & Public holidays: $2 \%$ \\
\hline
\end{tabular}




\begin{tabular}{|c|c|c|}
\hline Gender & Men: 49\%; Women: 51\% & 248 \\
\hline Handicap & No: 96\%; Yes: 4\% & \\
\hline \multirow{2}{*}{ Familytype } & Single: $19 \%$ & Couple: $31 \%$ \\
\hline & Single with children: $7 \%$ & Couple with children: $44 \%$ \\
\hline \multirow[t]{4}{*}{ Education: } & 7th-10th grade: $23 \%$ & Short further education: $22 \%$ \\
\hline & High school level: 11\% & Medium length further education: $6 \%$ \\
\hline & Vocational training: $2 \%$ & Long cycle higher education: 25\% \\
\hline & & Other: $12 \%$ \\
\hline \multirow[t]{2}{*}{ Occupation } & Student: $18 \%$ & Free-lancer: 5\% \\
\hline & Employee: $51 \%$ & Other: $26 \%$ \\
\hline Age & Mean: 43 & SD: 19 \\
\hline Family income & Mean: 63,000 EUR/year & SD: 45,000 EUR \\
\hline City density & Mean: 26 pop/Ha & SD: $21 \mathrm{pop} / \mathrm{Ha}$ \\
\hline City size (population) & Mean: 273,000 & SD: 482,000 \\
\hline Cycling grants & Mean: 1.5 million EUR & SD: 3.1 million EUR \\
\hline Cycling grants for national roads & Mean: 0.11 million EUR & SD: 0.4 million EUR \\
\hline Local campaign activities & Mean: 0.5 & SD: 3 \\
\hline National campaign activities & Mean: 1.5 & SD: 3.5 \\
\hline
\end{tabular}

Notes. The TU sample included trips from June 2010 to June 2017, a total of 234,352 trips.

Table 3: Descriptive statistics for the KU dataset.

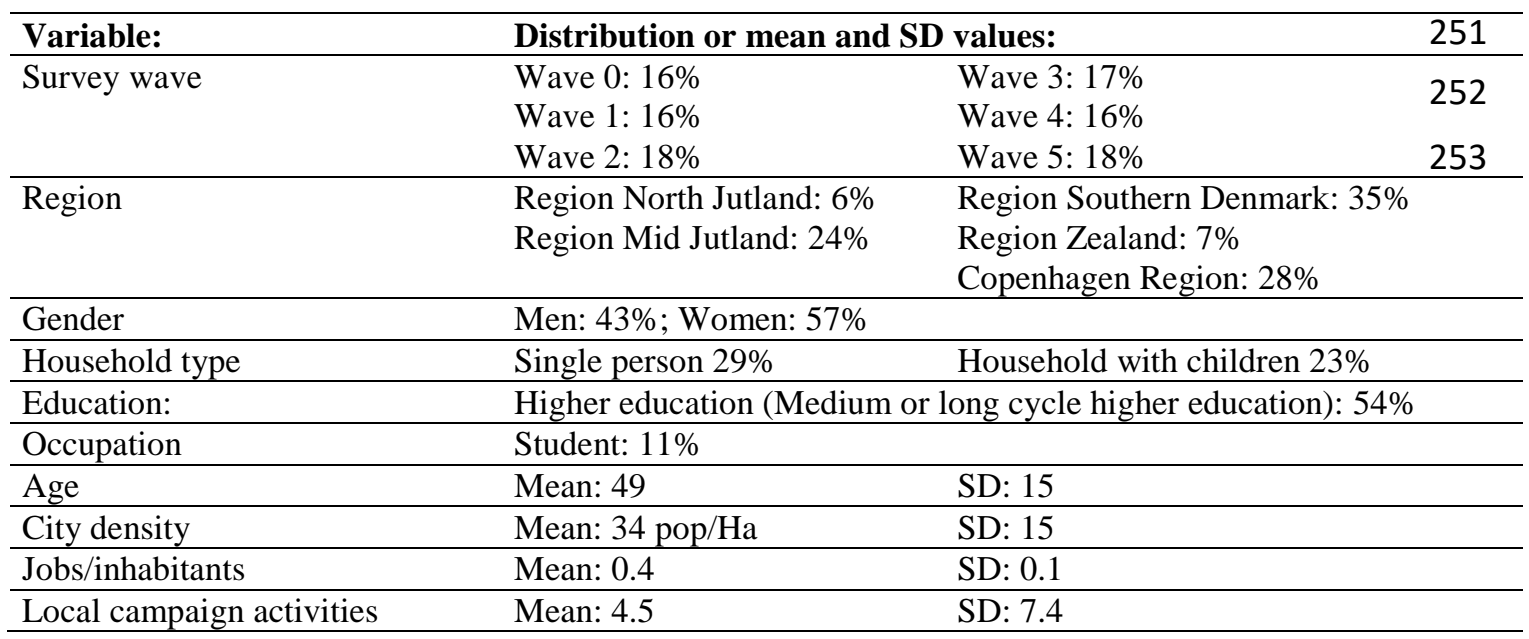

Notes. The KU sample included 11,798 respondents surveyed in six separate survey waves

255 between February 2015 and June 2017. Figure 2 shows the timing of each wave.

$257 \quad$ 4. Results

\subsection{Descriptive results}

\subsubsection{Campaign awareness}

In each KU survey wave, people were asked if they had ever seen or heard about the 261 campaign. On a national level, the awareness increased from a base level of 16\% before the campaign, to $21 \%$ in the third survey wave, and decreased again to $19 \%$ at the end of the 
263 campaign. In the partner municipalities, awareness partly reached values around 40\%

264 (Middelfart \& Odense), as can be seen in Figure 3.

The high level of awareness before the campaign represents 'false positives' as the 266 campaign was not public at the time. Such responses are common when respondents are asked 267 about their knowledge of a specific item. The changes over the survey waves does, however, 268 indicate real increases in the awareness of the campaign over time.

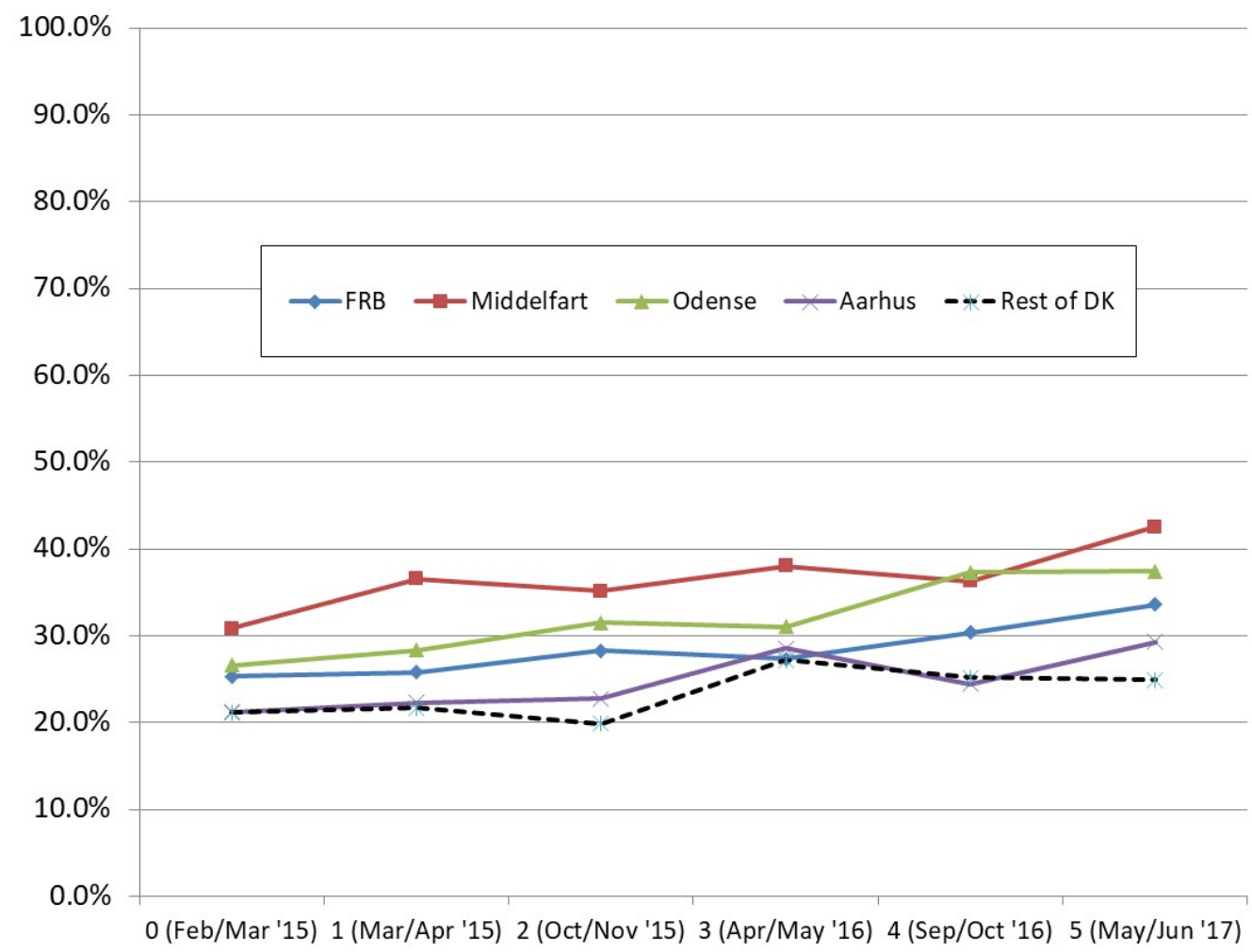

Figure 3: Percentage of people aware of the campaign during the project period.

\section{$272 \quad$ 4.1.2 Cycling frequency}

This section provides descriptive results for the two dependent variables that we used in 274 the regression analyses in Section 3.2.

Figure 4 shows the percentage of cycling trips in three of the four partner municipalities compared to the rest of Denmark for the time period that was included in the regression analysis

277 (2010-2017). Middelfart is not included here, as the data base is too small. The figure shows 278 diverse trends between the three municipalities which is also likely to be related to the high 
279 uncertainty that is associated with producing an annual estimate for each municipality. A trend

280 can be established with the highest degree of certainty for the municipalities that were not

281 partners of the campaign. Here the trend is negative and the cycling share of trips is declining

282 over time $(\mathrm{p}<0.001)$. By contrast, the municipality of Aarhus displays a slight positive trend

283 towards an increasing cycling share over time $(\mathrm{p}<0.001)$, but trends for Frederiksberg and

284 Odense remain insignificant.

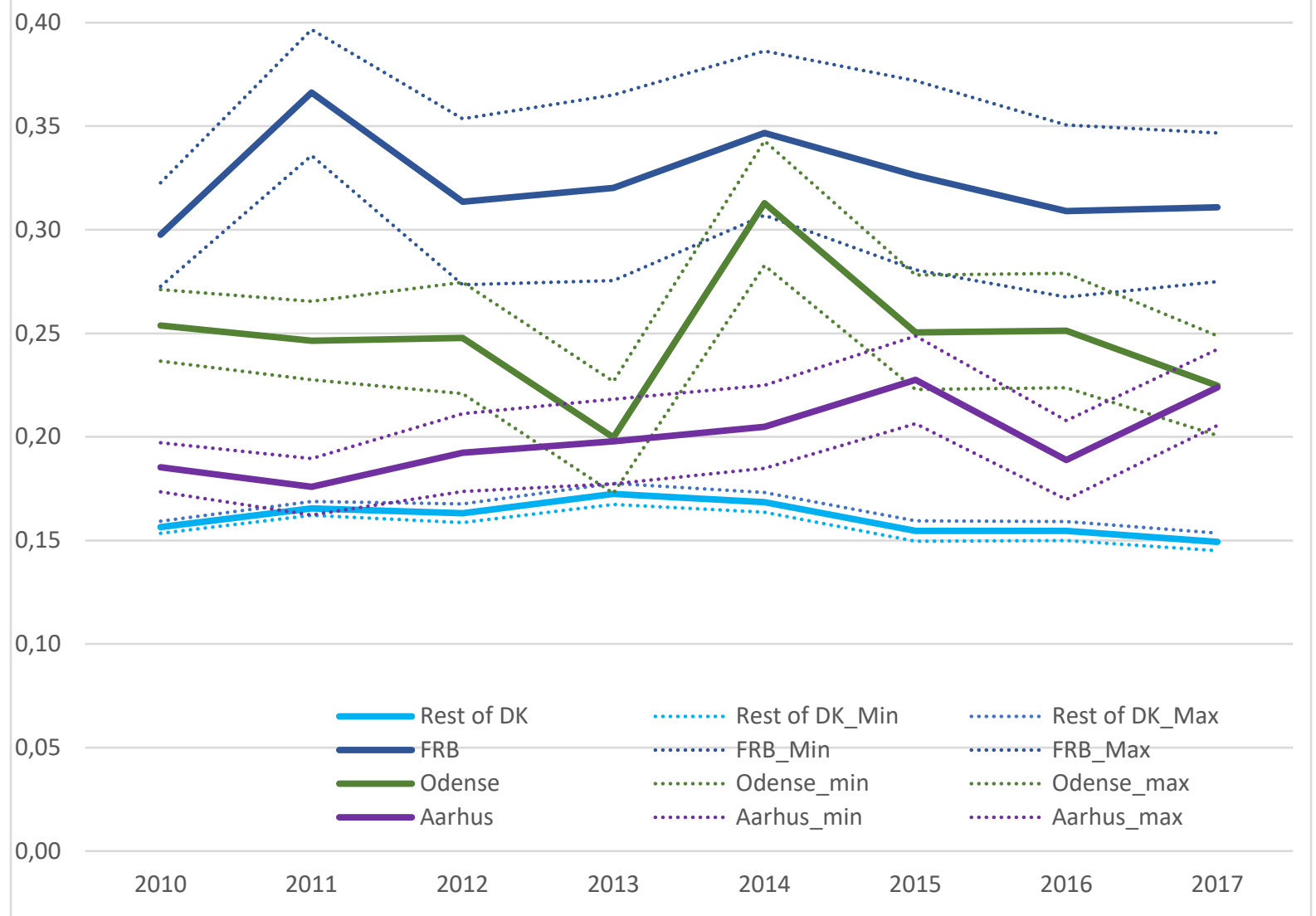

Figure 4: Share of all trips that involves the use of a bicycle calculated from TU data 2010-2017 by municipality and survey year.

Notes: 'Min' and 'Max' refer to the 95\% confidence interval of the mean. municipalities compared to the rest of Denmark for all six waves of data collection based on KU.

291 The differences between the six survey waves might partly reflect seasonal effects and partly

292 campaign effects. Based on the descriptive results alone, it is not possible to estimate the 293 campaign effect. 


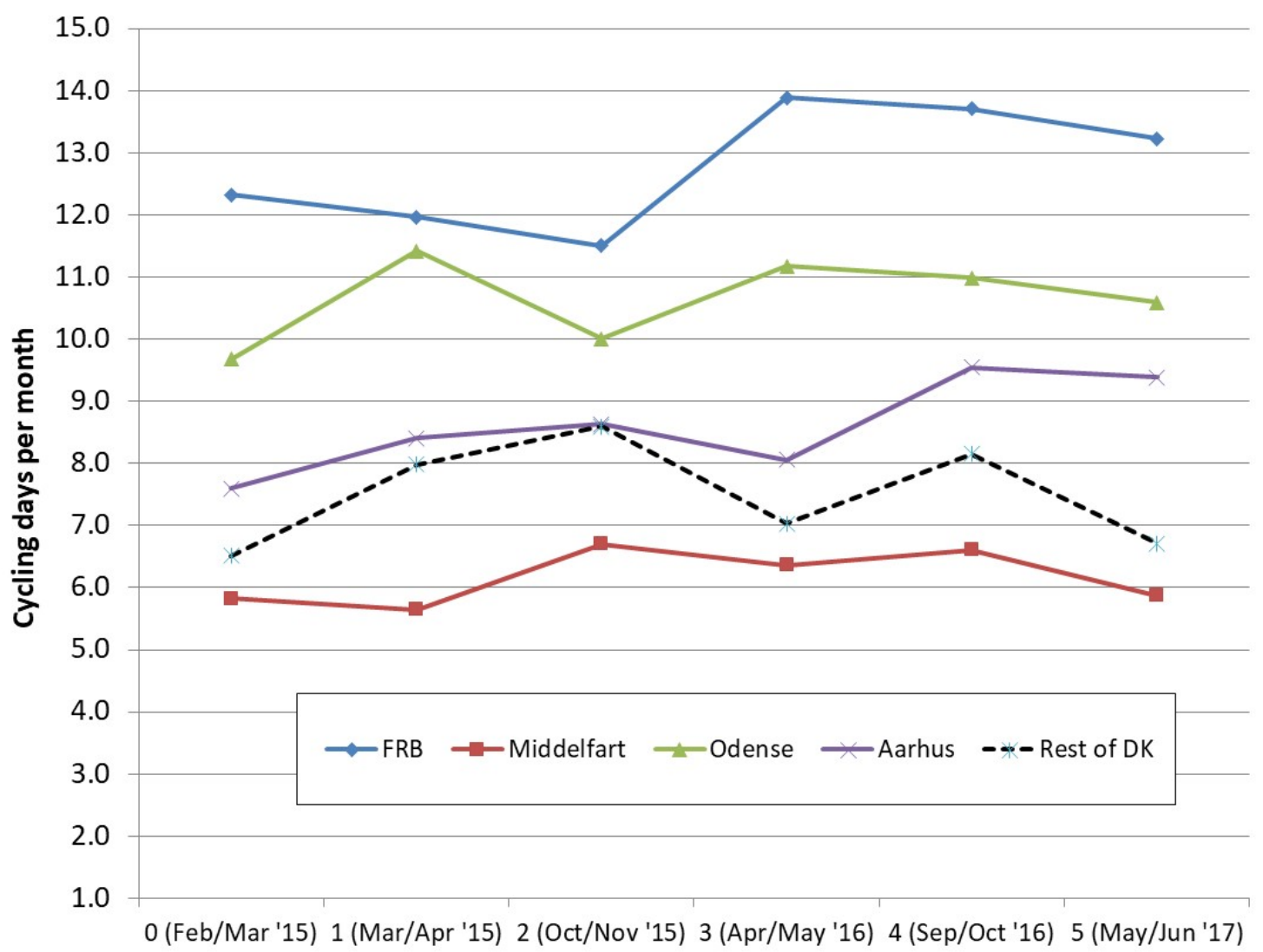

Figure 5: Number of cycling days per month ${ }^{1}$ in the partner municipalities and the rest of Denmark based on KU survey data.

\subsection{Behavioural effect assessment}

To estimate the behaviour effects from the cycling campaign, we calculated two regression analyses, one logistic regression analysis based on the trips registered in TU data

301 (cycling trip or not, see Table 4), and one linear regression based on the self-reported number of 302 cycling days per person that took part in the KU survey (see Table 5). In both analyses we 303 controlled for demographic variables, spatial/regional effects, and time effects (TU: month/ KU: wave of data collection).

The regression in Table 4 is based on 154.817 trips conducted between July 2010 and 306 July 2017. The model controls for the survey year and month and thereby for general changes in 307 the probability of cycling as well as seasonal variation. In addition, the model controls for

\footnotetext{
${ }^{1}$ In the survey, the number of trips were assessed in categories, which were afterwards transformed into cycling days per month (e.g., every day $=29.7$; 3-4 days per month $=3.5$ ) for the analysis.
} 
regional effects, population density, density of bicycle infrastructures, and city/municipality size, which can also be relevant for the probability of cycling.

To control for other 'competing' efforts to increase cycling, which may also have contributed to changes in cycling, we included a measure of the project volume that had been funded by the national 'Bicycle fund' (Transportministeriet 2009-2015) in each municipality. As only knowledge on the time of funding was provided (and not the project duration etc.), we assumed a two year lag from grant to 'effect' as these projects generally have changes to the infrastructure as a core component.

Measures of campaign activities were included in the regression analysis in form of the cumulated number of campaign activities in the municipality from the beginning of the campaign until the time of the survey. A similar approach was applied to the national campaign activities, but the same cumulated campaign activity would here apply to all municipalities as these activities cannot be assigned to a specific geography, but rather were accessible to all with Danish language skills.

The model shows a significant positive effect of the local campaign activities on the likelihood to cycle. The same does not apply to the national campaign activities. This variable has less variation and it is very likely that the national activities and communication channels easily 'drowns' in noise from other activities. It can also be argued that key elements from the national campaign efforts, especially the cycling coach, has been promoted through the local activities where volunteers and the local health sector has played a role in increasing awareness. Large parts of the national activities are therefore expected to be reflected in the local campaign activities.

The effect of local campaign activities reflected in the model can be interpreted as a small effect compared to many other variables. However, a small additive effect from campaign activities should generally be expected compared to the many well-established factors affecting cycling, including weather/season, income and urban density.

Other variables and effects in the model include positive effects from other investments in cycling, as well as positive effects from cycling infrastructures, urban density, city size, and negative effects from being part of the highly integrated urban regions where more trips exceed 
cycling range. The model additionally includes general differences from year to year, the seasons of the year, daytypes during the week, and socio-demographic variables that may see some change over the years or between the survey waves and therefore should be included as control variables in the analysis.

To test the overall results presented in Table 4, we prepared a number of alternative editions of the main regression model. As only few control variables (including general differences from year to year and the project volume in each municipality that has received support from the national cycling fund) are able to represent changes over time, it is a necessary speculation, whether the effect of the campaign variable reflected in the regression model, can be due to specific conditions or changes in the municipalities with campaign activities that are not related to the campaign. To challenge the campaign effect of the main model in Table 4, we first prepared an alternative model with a variable that indicated whether or not campaign activities had taken place in the municipality $(0,1)$. This indicated that the campaigning municipalities generally have higher cycling rates than other municipalities, but only a smaller fraction of the correlation with the campaign variable can be attributed to this difference (B for local campaign activities $=0.008$ compared to 0.01 in the original model in Table 4).

In a further step, we prepared a second alternative model to test whether considering time trends or differences from year to year that are specific to the group of campaigning municipalities could be important to the result (by including the variable: Year * local campaign activities 0,1 ). The assumption would here be that the municipalities with campaign activities could have a different development trend for cycling over the years, which may generate a spurious correlation between campaign activities and cycling if not taken into consideration. The alternative model indicated that the campaigning municipalities do tend to have a higher cycling frequency in all years, with some variations, but also that taking this into consideration does not reduce the effect of the campaign variable in the model. As a final test, we prepared an alternative model to test how an assumption of linear time trends that are specific for each of the four partner municipalities, where most of the local campaign activities took place, influenced tha campaign effect in the model (we included four new variables in the model, one timevariable for each municipality). This specification of the model assumes that there could be specific levels and itineraries/trends for the development in cycling in each municipality that 
367 could accidently influence the correlation between campaign activities and cycling in the model 368 and therefore should be accounted for before considering campaign effects. The regression 369 results indicated significant trends in Odense, Aarhus (+) and Frederiksberg (-) but no significant 370 trend in Middelfart. The joint recognition of level and trend differences among the partner 371 municipalities that is included in this alternative model also removes effect from the campaign 372 variable and increases uncertainty (controlling for specific trends in the four municipalities leads 373 to a campaign effect parameter estimate (B) of 0.004 compared to 0.01 in the original model in 374 Table 4). However, this alternative specification also represents the highest degree of endogenity 375 that can be handled if there is to be any room to estimate the campaign effect, and there is an 376 obvious 'conflict' between the control variables being specific to municipalities and the 377 magnitudes of difference in campaign activities between municipalities. 
Table 4: Logistic regression analysis modelling whether or not a trip was a cycling trip

\begin{tabular}{|c|c|c|}
\hline Variable & $B$ & Sig. \\
\hline Survey year (2010-2017, df=7) & & .000 \\
\hline Month (January-December, df=11) & & .000 \\
\hline Type of day (Weekdays Mon-Thur, Friday, Weekdays in holidays, & & .000 \\
\hline \multicolumn{3}{|l|}{$\begin{array}{l}\text { Saturdays, Sundays, Holidays or Sundays preceding weekends or } \\
\text { holidays, } \mathrm{df}=5 \text { ) }\end{array}$} \\
\hline Gender (Woman=1, Man=0) & .107 & .000 \\
\hline Age & -.008 & .009 \\
\hline Age squared & .000 & .041 \\
\hline $\begin{array}{l}\text { Type of education ( }<7 \text { th grade, 8th, 9th, 10th, high school, higher } \\
\text { tech. exam, vocational training, short-, medium, or long (university) } \\
\text { further education, other; } d f=10 \text { ) }\end{array}$ & & .000 \\
\hline Handicap $(0,1)$ & .684 & .000 \\
\hline Type of housing $(\mathrm{df}=5)$ & & .160 \\
\hline Family type $(\mathrm{df}=3)$ & & .000 \\
\hline single, single w. child(ren), couple, couple w. child(ren), & & \\
\hline Children below 6 year of age in the household $(0,1)$ & .092 & .000 \\
\hline $\begin{array}{l}\text { Type of occupation (student, employee, free-lancer, unemployed, } \\
\mathrm{df}=3 \text { ) }\end{array}$ & & .000 \\
\hline Family income per adult (in thousands year 2000 DKK) & -.001 & .000 \\
\hline City density (persons/Ha of city area) & .007 & .000 \\
\hline Cycle path density (km path/lane /square metre city area) & .122 & .000 \\
\hline Capital region $(0,1)$ & -.257 & .000 \\
\hline East Jutland (the urban region from Randers to Haderslev, 0,1) & -.256 & .000 \\
\hline City size (LN population) & .123 & .000 \\
\hline Sum in million DKK for local cycling projects granted 2010-2015. & .004 & .000 \\
\hline Grants expected to have an effect with 2-years delay & & \\
\hline $\begin{array}{l}\text { Sum in million DKK for national cycling projects granted 2010- } \\
\text { 2015. Grants expected to have an effect with 2-years delay }\end{array}$ & .007 & .034 \\
\hline Cumulative campaign intensity in each municipality 2015-2017 & .010 & .000 \\
\hline Cumulative national campaign intensity 2015-2017 & -.003 & .688 \\
\hline Constant & -5.610 & .000 \\
\hline
\end{tabular}

Notes: DKK= Danish kroner. Empty cells: Betas for categorical variable with more than two

380 categories are not provided but can be found in the appendix.

383 regional/spatial and time-related factors. The highest effect on the number of cycling days is the city density, which is not surprising as Copenhagen - the capital of Denmark - is by far the city with the highest percentage of cycling trips. Like the TU model, also the KU models shows a 386 small but significant positive effect of the cycling campaign intensity. Based on KU data it is not 
387 possible to examine the effect of the national campaign intensity as it is highly correlated with

388 the wave of data collection, which is needed as a variable in the model to control for general

389 changes and seasonal variations in cycling. The KU data is in this respect less 'flexible' than the

390 TU data that samples the seasonal variation through the year.

391 Table 5: Linear regression analysis modelling cycling days per month

\begin{tabular}{lccc}
\hline Variable & $\boldsymbol{B}$ & Stand. coefficients $\boldsymbol{\beta}$ & Sig. \\
\hline Gender & .092 & -.003 & .620 \\
Age & -.109 & -.152 & .023 \\
Age squared & .001 & .063 & .046 \\
Longer higher education (0,1) & 1.065 & .015 & .000 \\
Occupation: student (0,1) & 3.528 & .070 & .000 \\
Family type: single (0,1) & .687 & .023 & .003 \\
Family type: with children (0,1) & .006 & -.016 & .981 \\
Wave 1: Apr. 2015 & 1.084 & .034 & .001 \\
Wave 2: Nov. 2015 & 1.293 & .013 & .000 \\
Wave 3: May 2016 & .041 & -.013 & .898 \\
Wave 4: Sep. 2016 & 1.033 & .010 & .002 \\
Wave 5: June 2017 & -.478 & -.020 & .143 \\
Region North Jutland & -.042 & .017 & .916 \\
Region Mid Jutland & -.267 & .004 & .064 \\
Region Southern Denmark & .829 & .052 & .111 \\
Region Zealand & -.584 & -.013 & .000 \\
City density (persons/Ha) & .152 & .257 & .000 \\
Jobs/inhabitants & 3.923 & .027 & .000 \\
Cumulative campaign intensity in & .077 & .032 & .118 \\
each municipality_2015-2017 & & & \\
Constant & 1.914 & & \\
\hline
\end{tabular}

392

Based on the estimates for the cycling campaign in each model, we calculated its

394 equivalent in number of cycling days, trips and kilometres. The regression coefficient from the

395 KU model provide a direct way to calculate the added number of cycling trips per person for

396 each month and each municipality (converted from cycling days), which were then summarized

397 across the months in the campaign period and 'scaled' based on the populations of the

398 municipalities with campaign activities.

399 The TU based model supported a calculation of the probability of cycling in each

400 municipality and month, with and without (simulated) campaign activities, which was then

401 applied as a change in probability of cycling to the total number of trips. Changes to the total 
number of cycling trips related to the campaign were finally summarized across all campaign months and municipalities with campaign activities. Cycling days (KU) and trips (TU) were converted into trips and kilometres by applying the averages of the municipalities that could be derived from the TU dataset. Thus, one day with the use of a bicycle corresponds to 2.3-2.8 bicycle trips and 4.5-10.1 kilometres on bicycle, and one bicycle trip corresponds to 1.9-3.9 kilometres on bicycle.

Table 6 shows the estimates of total effects of campaign activities including the confidence interval derived from the parameter estimates’ standard errors.

Table 6: Estimated effects for the whole campaign period (February 2015 - July 2017) Estimated based on KU data:

\begin{tabular}{lll} 
& Average & Interval \\
\hline Cycling days & 16.1 million & {$[8-24$ million] } \\
Cycling trips & 42.5 million & [21-64 million] \\
Cycling km & 153 million & {$[75-230$ million] } \\
\hline
\end{tabular}

Estimated based on TU data:

\begin{tabular}{lll} 
& Average & Interval \\
\hline Cycling trips & 42.5 millionl & {$[24-62$ million $]$} \\
Cycling km & 146 million & {$[81-213$ million $]$} \\
\hline
\end{tabular}

1

12

The mean estimates of the number of cycling trips based on the two datasets and regression models are surprisingly close and can be taken as a validation of the 'realness' of the differences in cycling rates and changes reflected in the models. Based on the two sets of estimates, between 21 million and 64 million cycling trips could be attributed to the almost two and a half years of campaign activities in eleven municipalities with the original four partner municipalities as the core where most campaign activities took place. A general uncertainty imposed by the possibility of other efforts to promote cycling in the municipalities, which are not represented in the data, must be accepted.

As the additional model specifications that included control for the municipalities' participation in the campaign (thus testing a hypothesis of special attributes of campaign municipalities, i.e. self-selection, being the explanation behind the apparent campaign effect) and 
423 time trends specific to each of the four partner municipalities (testing a hypothesis of whether

424 longer term trends/itineraries for cycling frequencies in individual municipalities could be the 425 explanation behind the apparent campaign effect) have reduced the effect estimate, we find it 426 reasonable to refer to the low end of the interval of cycling trips as what can be attributed to the 427 campaign.

\section{Discussion and conclusions}

With the main motivation to improvepeople's health through increased physical activity, an extensive two and a half years cycling campaign was conducted in Denmark. Local activities were concentrated within four partner municipalities across the country and after one year, they were supplemented by national campaigns, including the launch of the "cycling coach" - a customised app to support people in setting personal goals for cycling and achieving them. To motivate people to cycle, the campaign mainly focused on the positive effects of cycling.

We have measured campaign effects based on repeated independent samples as they were available from the Danish national travel survey and a separate survey, which was setup as part

437 of the project evaluation. While these are large and representative datasets, panels are often perceived as the more desirable solution. However, they have other problems in terms of costs, 439 representatively and drop-out.

We identified significant positive effects of the campaign based on both datasets, and the independent estimations led to very similar results, which support the conclusion of significant

442 differences between the campaigning municipalities and other municipalities.

While the ambitious campaign goal of 50 million additional cycling trips per year could

444 not be reached, our results point to additional 21 million cycling trips during the campaign period 445 as a cautious effect estimate, which means an increase by circa one percentage. The overall 446 health effect of these additional cycling trips depends on which people have been reached by the 447 campaign: is it mainly people who increased existing levels of cycling, or rather people who did 448 not cycle before, which would have the more positive health outcome. It also makes a difference 449 from which transport mode they switched to cycling; however, this was out of the scope of this 450 study. 
Examples of effect studies of large or national campaigns in Denmark include Troelsens et al.’s (2004) assessment of changes in cycling during the project 'Odense Cykelby’. Conclusions drawn from TU-based analysis of changes in cycling among Odense residents (controlling for changes in other locations) pointed to a total increase of 35 million cycling trips in the municipality of Odense during the three project years (corresponding to 129 million kilometres on bicycle if an average cycling distance is assumed). Additionally, Willumsen and Duer's (2012) assessment of the effects of the national 'Bike-to-Work' campaign in 2011 pointed to an increase of 29.5 million kilometres on bicycle based on 93.000 participants and their self-reported changes. Comparing these assessments to campaign costs results in direct campaign cost of between 0.08 EUR (Odense) and 0.2 EUR (Bike-to-work) per additional bike trip. Based on the conservative estimate of 21 million additional bike-trips, our estimate corresponds to a direct campaign budget cost of 0.07 EUR per bike trip. This is slightly less than in 'Odense Cykelby', which may be explained by the larger audience and reach of a campaign across several municipalities. However, real estimates of resource inputs to the campaign are difficult to assess due to the use of unpaid volunteers from the health organisations as a key resource to carry out local events.

As a limitation to the study, the operationalisation of the local campaign intensity can be pointed out. We measured the local campaign intensity by summing up the number of locations with campaign activities per municipality per month. One can expect that it makes a difference, how information was distributed to the households in a municipality and how well locations with campaign activities were connected to the local activity centres to maximise exposure. It will also depend on the number of volunteers at a location and their motivation and engagement, how many people will be reached and if they can be motivated to increase cycling or not.

Originally, a much more detailed measurement of campaign activities was planned. However, too high requirements in the documentation of (mostly) volunteers' engagement appeared to be counterproductive in this study and the requirements were thus adapted in the process. Still, activities were not registered at the same level of detail in all municipalities, so that the lowest common denominator was the municipality name, activity description and the month of implementation. When wanting to achieve a more precise measurement, it would be relevant to have additional (paid) staff to observe and document the local activities in more 
481 detail. One could then distinguish between the number of people contacted personally, by mail, the number of information material distributed and the number of (different kinds of) incentives and could thereby also get information about which measure leads to the greatest effects.

While web-applications and social media activities are regarded as important campaign elements, they constitute a problem when it comes to the effect assessment. We have considered these elements to be national campaign activities as their geography is principally unlimited and based the measure on launches/quests, where each launch/quest counts as one activity. A more precise measurement would, for example, include the number of views but this information is restricted and unavailable to the campaign evaluation.

A more practical lesson to be learned from the implementation of this campaign is that it takes time to establish a strong partnership across sectors. With different partners, having their own agenda for promoting bicycling, it took some negotiations to find a common content for the campaign. Nevertheless, the campaign succeeded having a common tone of voice and message. Through the partnership's diverse communication channels, the campaign reached a broad target group and enhanced bicycle trips across the country. The high reach and measurable effect might also be related to the fact that elements of the campaign were relevant for people at different stages in the process of behaviour change: Local activities and media reports focused on awareness raising, the cycling coach first helped to set personal goals, then providing feedback and social support and thereby motivated people to reach their goals and maintain the new behaviour.

\section{Acknowledgment}

This research was supported by Nordea-fonden and the Danish Road Directorate. We thank the Danish Cancer Society, in particular Hanne Munk Scheller, Vibeke Berglund Gunge, Gitte Laub Hansen, and Iben Sommer for their project coordination and practical support throughout the project period. In addition, we thank all project partners who contributed to the realisation of the campaign: The Danish Heart Foundation, The Danish Diabetes Association, the City of Aarhus, the City of Odense, the City of Middelfart, City of Frederiksberg, the Danish Cyclists’ Federation, DSB, and Movia. Finally, we thank all volunteers associated with the partner organisations who actively contributed to the success of the campaign. 


\section{References}

Arnott, B., Rehackova, L., Errington, L., Sniehotta, F. F., Roberts, J., \& Araujo-Soares, V. (2014). Efficacy of behavioural interventions for transport behaviour change: systematic review, meta-analysis and intervention coding. International Journal of Behavioral Nutrition and Physical Activity, 11(1), 133.

Bamberg, S., Fujii, S., Friman, M., \& Gärling, T. (2011). Behaviour theory and soft transport policy measures. Transport Policy, 18(1), 228-235.

Bird, E. L., Baker, G., Mutrie, N., Ogilvie, D., Sahlqvist, S., \& Powell, J. (2013). Behavior change techniques used to promote walking and cycling: A systematic review. Health Psychology, 32(8), 829.

Brown, V., Diomedi, B. Z., Moodie, M., Veerman, J. L., \& Carter, R. (2016). A systematic review of economic analyses of active transport interventions that include physical activity benefits. Transport Policy, 45, 190-208.

Christiansen, H. \& Skougaard, B., Z. (2015). Documentation of the Danish National Travel Survey (2015 version). DTU Transport. Retrieved from: http://orbit.dtu.dk/files/126120007/TU_english_version_2015.pdf

de Nazelle, A., Nieuwenhuijsen, M. J., Antó, J. M., Brauer, M., Briggs, D., Braun-Fahrlander, C. et al. (2011). Improving health through policies that promote active travel: A review of evidence to support integrated health impact assessment. Environment International, 37(4), 766-777.Deenihan, G., \& Caulfield, B. (2014). Estimating the health economic benefits of cycling. Journal of Transport \& Health, 1(2), 141-149.

de Hartog, J. J., Boogaard, H., Nijland, H., \& Hoek, G. (2010). Do the health benefits of cycling outweigh the risks? Environmental Health Perspectives, 118(8), 1109.

Gatersleben, B., \& Appleton, K. M. (2007). Contemplating cycling to work: Attitudes and perceptions in different stages of change. Transportation Research Part A: Policy and Practice, 41(4), 302-312.

Haustein, S., \& Nielsen, T. A. S. (2016). European mobility cultures: A survey-based cluster analysis across 28 European countries. Journal of Transport Geography, 54, 173-180. 
Jacobsen, P. L. (2003). Safety in numbers: more walkers and bicyclists, safer walking and bicycling. Injury Prevention, 9(3), 205-209.

Johansson, C., Lövenheim, B., Schantz, P., Wahlgren, L., Almström, P., Markstedt, A., Strömgren, M., Forsberg, B., \& Sommar, J. N. (2017). Impacts on air pollution and health by changing commuting from car to bicycle. Science of the Total Environment, 584, 5563.

Lanzendorf, M., \& Busch-Geertsema, A. (2014). The cycling boom in large German citiesempirical evidence for successful cycling campaigns. Transport Policy, 36, 26-33.

Laverty, A. A., Mindell, J. S., Webb, E. A., \& Millett, C. (2013). Active travel to work and cardiovascular risk factors in the United Kingdom. American Journal of Preventive Medicine, 45(3), 282-288.

Millett, C., Agrawal, S., Sullivan, R., Vaz, M., Kurpad, A., Bharathi, A. V. et al. (2013). Associations between active travel to work and overweight, hypertension, and diabetes in India: a cross-sectional study. PLoS Medicine, 10(6), e1001459.

Mueller, N., Rojas-Rueda, D., Cole-Hunter, T., de Nazelle, A., Dons, E., Gerike, R. et al. (2015). Health impact assessment of active transportation: A systematic review. Preventive Medicine, 76, 103-114.

Olafsson, A.S., Nielsen, T.S., \& Carstensen, T.A. (2016). Cycling in multimodal transport behaviours: Exploring modality styles in the Danish population, Journal of Transport Geography, 52, 123-130.

Pucher, J., Buehler, R., Bassett, D. R., \& Dannenberg, A. L. (2010). Walking and cycling to health: a comparative analysis of city, state, and international data. American Journal of Public Health, 100(10), 1986-1992.

Pucher, J., Dill, J., \& Handy, S. (2010). Infrastructure, programs, and policies to increase bicycling: an international review. Preventive Medicine, 50, S106-S125.

Rabl, A., \& De Nazelle, A. (2012). Benefits of shift from car to active transport. Transport Policy, 19(1), 121-131. 
Scheepers, C. E., Wendel-Vos, G. C. W., Den Broeder, J. M., Van Kempen, E. E. M. M., Van Wesemael, P. J. V., \& Schuit, A. J. (2014). Shifting from car to active transport: a systematic review of the effectiveness of interventions. Transportation Research Part A: Policy and Practice, 70, 264-280.

Stewart, G., Anokye, N. K., \& Pokhrel, S. (2015). What interventions increase commuter cycling? A systematic review. BMJ open, 5(8), e007945.

Transportministeriet, 2009. Aftaler om En grøn transportpolitik 2009, Transportministeriet: København

Transportministeriet, 2010. Aftaler om En grøn transportpolitik 2010, Transportministeriet: København

Transportministeriet, 2011. Aftaler om En grøn transportpolitik 2011, Transportministeriet: København

Transportministeriet, 2012. Aftaler om En grøn transportpolitik 2012, Transportministeriet: København

Transportministeriet, 2013. Aftaler om En grøn transportpolitik 2013, Transportministeriet: København

Transportministeriet, 2014. Aftaler om En grøn transportpolitik 2014, Transportministeriet: København

Transportministeriet, 2015. Aftaler om En grøn transportpolitik 2015-2016, Transportministeriet: København

Troelsen, J., Jensen, S.U., Andersen, T. (2004). Evaluering af Odense - Danmarks Nationale Cykelby, Odense Kommune: Odense

Willumsen, E., \& Duer, H. (2012). Samfundsøkonomisk vurdering af "Vi cykler på arbejde”kampagnen, Artikler fra Trafikdage på Aalborg Universitet. Retrieved from: www.trafikdage.dk/artikelarkiv (19-06-2018)

Yang, L., Sahlqvist, S., McMinn, A., Griffin, S. J., \& Ogilvie, D. (2010). Interventions to promote cycling: systematic review. BMJ, 341, c5293. 